\title{
Immunologic Reconstitution After Rituximab in Systemic Lupus Erythematosus: Why Should We Care?
}

There is great interest in the role of B cells in autoimmune inflammatory diseases, running the spectrum from traditionally viewed B cell-centric diseases such as systemic lupus erythematosus (SLE) to rheumatoid arthritis (RA) to conventionally viewed $\mathrm{T}$ cell-mediated conditions such as multiple sclerosis. Although there is controversy regarding the place of B cell depletion in the SLE treatment armamentarium given the failure of 2 recent placebo-controlled trials (EXPLORER and LUNAR $)^{1}$, this therapy is still used in the rheumatology community, particularly for refractory disease. Given the variability in response, I would argue that it is even more critical to understand how B cell depletion is efficacious and whether there are subsets of patients who will respond particularly well to B cell approaches as opposed to other treatment modalities.

The article by Iwata and colleagues ${ }^{2}$ in this issue of The Journal examines changes in peripheral blood B and T cells longitudinally in 10 patients with active SLE treated with rituximab and attempts to correlate these changes with clinical response and relapse. A central finding is that prolonged remissions (in 8/10 patients) are associated with prolonged reductions in the fractions of both memory $\mathrm{B}$ and $\mathrm{T}$ cells, as well as downregulation of activation markers, including CD80 on B cells and CD40L, CD69, and inducible costimulator (ICOS) on T cells. An unfortunate omission is the absence of flow cytometry analysis in the 2 nonresponders. Other limitations of their study include the small numbers of patients studied, the limited $\mathrm{T}$ cell analyses (no $\mathrm{T}$ regulatory or $\mathrm{T}$ helper cell data), and incomplete definition of $\mathrm{B}$ cell subsets, with a notable lack of consideration of transitional $\mathrm{B}$ cells. Interestingly, in the 2 patients (of 8 responders) with flares of disease over the 2 years of the study, distinct patterns were observed with an activated memory B cell phenotype at flare in one patient versus a CD4+ memory $\mathrm{T}$ cell resurgence in the other. The authors suggest a B cell versus $\mathrm{T}$ cell dominant SLE, which may guide therapeutic decision-making, although this would not explain the initial response of both patients to B cell depletion therapy. On the other hand, even with $\mathrm{T}$ cell dominant disease, B cell depletion therapy may be effective by altering the $\mathrm{T}$ cell compartment, as suggested by a rapid (Day 28) and prolonged (Year 2) reduction in CD40L and ICOS on T cells and a prolonged decrease in memory $\mathrm{T}$ cells.

This work highlights the importance of antibody-independent roles for B cells in autoimmunity, which is often underappreciated. The critical role of antibody-independent $\mathrm{B}$ cell functions is well demonstrated by the fact that $\mathrm{B}$ cells are critical to the development of murine lupus even when they are unable to secrete autoantibodies ${ }^{3}$. Moreover, in at least some human autoimmune diseases including SLE the efficacy of B cell depletion is often dissociated from changes in autoantibodies. In this regard, it would be helpful to know what happened to autoantibodies in the context of the present study. Finally, the most compelling efficacy data for B cell depletion is in diseases that are traditionally viewed as $\mathrm{T}$ cell-driven (RA and multiple sclerosis, for example), suggesting a role for B cells in regulating other immune cells. It has been suggested that B cells may participate in immune dysregulation at multiple levels by presenting antigens and providing costimulatory signals to $\mathrm{T}$ cells and helping to regulate and organize inflammatory responses through cytokine and chemokine secretion [such as interleukin 10 (IL-10), IL-6, interferon- $\gamma$, and lymphotoxin- $\alpha]^{4,5}$. The present article adds to rather limited data indicating that effects on the $\mathrm{T}$ cell compartment may be key to responses in human SLE after B cell depletion therapy ${ }^{6,7}$. These data include the variable finding of increased regulatory $\mathrm{T}$ cells after $\mathrm{B}$ cell depletion ${ }^{7}$, decreased $\mathrm{T}$ cell activation $^{6}$, and a shift in the Th1/Th2 balance ${ }^{8}$. Of note, in contrast to the study by Sfikakis, et $a l^{6}$ the decreased $\mathrm{T}$ cell activation observed in the present study was not confounded by high-dose steroids. There is also an expanding literature in murine autoimmunity to support an effect of B cell depletion on the $\mathrm{T}$ cell compartment, including decreased CD4 $\mathrm{T}$ cell autoreactivity, decreased CD4 and CD8 T cell responses, and expansion of $\mathrm{T}$ regulatory cells.

See Phenotypic changes of lymphocytes in longterm SLE remission after rituximab, page 633 
The study by Iwata and colleagues ${ }^{2}$ confirms our finding that longterm remission in SLE patients treated with B cell depletion therapy is associated with a prolonged paucity of memory B cells and a reconstitution dominated by "naive" B cells ${ }^{9,10}$. Unfortunately, the limited B cell phenotyping in the present study does not distinguish naive from transitional B cells (transitional B cells would be embedded in the naive IgD+CD27- population). In particular, we have proposed that a repopulation with transitional cells is associated with sustained clinical remission, while a quick resurgence of memory cells portends a poor outcome. These observations have been confirmed by other groups and also appear to apply to RA patients ${ }^{11}$. These results highlight an underappreciated point in the field that the therapeutic effect of B cell depletion therapy likely does not lie solely in the depletion of $\mathrm{B}$ cells but also in longterm reconstitution effects. Thus, although numerous examples of pathogenic roles for B cells have been provided by mouse models using either B cell-deficient mice or B cell depletion ${ }^{12,13}$, evidence is accumulating for regulatory $\mathrm{B}$ cells ${ }^{14}$ capable of preventing or suppressing autoimmunity in different mouse models ${ }^{15,16,17}$. This protective role can be mediated by inducing $\mathrm{T}$ cell anergy during antigen presentation or inducing Treg expansion or activity ${ }^{18}$. These activities are mediated, at least in part, by the production of IL-10 or transforming growth factor- $\beta$ and may control a variety of autoinflammatory diseases including inflammatory arthritis, inflammatory bowel disease, autoimmune diabetes, experimental autoimmune encephalitis, contact hypersensitivity, and SLE. Based on this model, one could envision that the clinical and immunological outcome of B cell depletion therapy will likely depend on the relative balance of protective and pathogenic B cell subsets established upon B cell repopulation.

The actual nature and mechanisms of action of human B regulatory cells remain unclear. Recently, Mauri and colleagues further defined a subset of CD24 high CD38 high transitional $\mathrm{B}$ cells with regulatory potential that inhibits CD4 Th1 differentiation and is impaired in function in $\mathrm{SLE}^{19}$. Our observation that expansion of transitional B cells correlates with longterm remission in SLE patients after B cell depletion therapy is consistent with restoration of regulatory function. However, it will be critical to formally demonstrate the regulatory function of this B cell population in SLE after B cell depletion. Along these lines it has been shown that IL-10 production is impaired in total B cells of patients with active multiple sclerosis and that a reversal of this deficit correlates with good response to B cell depletion ${ }^{20}$, again suggesting the emergence of an IL-10-secreting regulatory B cell population. Further, a recent study demonstrated a $B$ cell signature associated with renal transplant tolerance and increased IL-10 secretion by a putative regulatory transitional $\mathrm{B}$ cell population ${ }^{21}$. One could speculate that the naive predominant B cell compart- ment observed by Iwata and colleagues also represents a regulatory B cell expansion. However, a critical question that remains to be addressed is whether the benefit of $\mathrm{B}$ cell depletion is directly mediated by the expanded transitional cells or instead reflects the absence of effector B cells. The finding of memory B cell resurgence with flare in the study by Iwata and colleagues suggests that the absence of effector B cells is critical to disease remission, although we would speculate that longterm responses ultimately represent a rebalancing of protective versus pathogenic B cell subsets and functions.

\author{
JENNIFER ANOLIK, MD, $\mathrm{PhD}$, \\ Associate Professor of Medicine, \\ Division of Allergy, Immunology, Rheumatology, \\ Department of Medicine, \\ University of Rochester, \\ 601 Elmwood Ave, \\ Rochester, New York 14642, USA
}

Address correspondence to Dr. Anolik.

E-mail: jennifer_anolik@urmc.rochester.edu

The author has been supported by several grants including U19 Autoimmunity Center of Excellence AI56390, R01 AI077674-01A1, and the Lupus Research Institute. Dr. Anolik has served as a consultant for Genentech and Roche and has received grants for pre-clinical and translational studies from Proteolix and Amgen.

\section{REFERENCES}

1. Merrill JT, Neuwelt CM, Wallace DJ, Shanahan JC, Latinis KM, Oates JC, et al. Efficacy and safety of rituximab in moderately-to-severely active systemic lupus erythematosus: the randomized, double-blind, phase II/III systemic lupus erythematosus evaluation of rituximab trial. Arthritis Rheum 2010;62:222-33.

2. Iwata S, Saito K, Tokunaga M, Yamaoka K, Nawata M, Yukawa S, et al. Phenotypic changes of lymphocytes in patients with systemic lupus erythematosus who are in longterm remission after B cell depletion therapy with rituximab. J Rheumatol 2011;38:633-41.

3. Shlomchik MJ, Madaio MP, Ni D, Trounstein M, Huszar D. The role of B cells in lpr/lpr-induced autoimmunity. J Exp Med 1994;180:1295-306.

4. Mamula MJ, Fatenejad S, Craft J. B cells process and present lupus autoantigens that initiate autoimmune $\mathrm{T}$ cell responses. J Immunol 1994;152:1453-61.

5. Chan OT, Hannum LG, Haberman AM, Madaio MP, Shlomchik MJ. A novel mouse with B cells but lacking serum antibody reveals an antibody-independent role for B cells in murine lupus. J Exp Med 1999;189:1639-48.

6. Sfikakis PP, Boletis JN, Lionaki S, Vigklis V, Fragiadaki V, Iniotaki A, et al. Remission of proliferative lupus nephritis following B cell depletion therapy is preceded by down-regulation of the T cell costimulatory molecule CD40 ligand: An open-label trial. Arthritis Rheum 2005;52:501-13.

7. Stasi R, Cooper N, Del Poeta G, Stipa E, Laura Evangelista M, Abruzzese E, et al. Analysis of regulatory T-cell changes in patients with idiopathic thrombocytopenic purpura receiving B cell-depleting therapy with rituximab. Blood 2008;112:1147-50.

8. Tamimoto Y, Horiuchi T, Tsukamoto H, Otsuka J, Mitoma H, Kimoto Y, et al. A dose-escalation study of rituximab for treatment of systemic lupus erythematosus and Evans' syndrome: immunological analysis of B cells, T cells and cytokines. 
Rheumatology 2008;47:821-7.

9. Anolik JH, Friedberg JW, Zheng B, Barnard J, Owen T, Cushing $\mathrm{E}$, et al. B cell reconstitution after rituximab treatment of lymphoma recapitulates B cell ontogeny. Clin Immunol 2007; 122:139-45.

10. Anolik J, Barnard J, Owen T, Zheng B, Kemshett S, Looney J, et al. Delayed memory B cell recovery in peripheral blood and lymphoid tissue in systemic lupus erythematosus after B cell depletion therapy. Arthritis Rheum 2007;56:3044-56.

11. Leandro MJ, Cambridge G, Ehrenstein MR, Edwards JCW. Reconstitution of peripheral blood B cells after depletion with rituximab in patients with rheumatoid arthritis. Arthritis Rheum 2006;54:613-20.

12. Hamel K, Doodes P, Cao Y, Wang Y, Martinson J, Dunn R, et al. Suppression of proteoglycan-induced arthritis by anti-CD20 B cell depletion therapy is mediated by reduction in autoantibodies and CD4+ T cell reactivity. J Immunol 2008;180:4994-5003.

13. Bekar KW, Owen T, Dunn R, Ichikawa T, Wang W, Wang R, et al. Prolonged effects of short-term anti-CD20 B cell depletion therapy in murine systemic lupus erythematosus. Arthritis Rheum 2010; 62:2443-57.

14. Lund FE. Cytokine-producing B lymphocytes - key regulators of immunity. Curr Opin Immunol 2008;20:332-8.

15. Matsushita T, Yanaba K, Bouaziz JD, Fujimoto M, Tedder TF. Regulatory B cells inhibit EAE initiation in mice while other B cells promote disease progression. J Clin Invest 2008;118:3420-30.
16. Haas KM, Watanabe R, Matsushita T, Nakashima H, Ishiura N, Okochi $\mathrm{H}$, et al. Protective and pathogenic roles for B cells during systemic autoimmunity in NZB/W F1 mice. J Immunol 2010; 184:4789-800

17. Evans JG, Chavez-Rueda KA, Eddaoudi A, Meyer-Bahlburg A, Rawlings DJ, Ehrenstein MR, et al. Novel suppressive function of transitional 2 B cells in experimental arthritis. J Immunol 2007;178:7868-78.

18. Zhong X, Gao W, Degauque N, Bai C, Lu Y, Kenny J, et al. Reciprocal generation of Th1/Th17 and T(reg) cells by B1 and B2 B cells. Eur J Immunol 2007;37:2400-4.

19. Blair PA, Norena LY, Flores-Borja F, Rawlings DJ, Isenberg DA, Ehrenstein MR, et al. CD19(+)CD24(hi)CD38(hi) B cells exhibit regulatory capacity in healthy individuals but are functionally impaired in systemic lupus erythematosus patients. Immunity 2010;32:129-40.

20. Duddy M, Niino M, Adatia F, Hebert S, Freedman M, Atkins H, et al. Distinct effector cytokine profiles of memory and naive human $\mathrm{b}$ cell subsets and implication in multiple sclerosis. J Immunol 2007;178:6092-9.

21. Newell KA, Asare A, Kirk AD, Gisler TD, Bourcier K, Suthanthiran M, et al. Identification of a B cell signature associated with renal transplant tolerance in humans. J Clin Invest 2010;120:1836-47.

J Rheumatol 2011;38:587-9; doi:10.3899/jrheum.101350 